J. Lake Sci. (湖泊科学), 2014, 26(3):349-357

http://www. jlakes. org. E-mail : jlakes@niglas.ac.cn

(C) 2014 by Journal of Lake Sciences

\title{
富营养化湖泊围隔中重建水生植被及其生态效应”
}

\author{
胡 旭 ${ }^{1}$, 何 亮 $^{2}$, 曹 特 $^{2}$, 倪乐意 ${ }^{2}$, 谢 平 ${ }^{1,2 * *}$ \\ ( 1 : 华中农业大学水产学院,武汉 430070$)$ \\ ( 2 : 中国科学院水生生物研究所,武汉 430072)
}

\begin{abstract}
摘 要: 水体富营养化导致水生植被衰退、蓝藻水华暴发、水质恶化和水生生态系统崩溃. 恢复水生植被被认为是改善受 损水体水质和提高其生态系统稳定性的重要手段. 本研究通过构建大型围隔, 根据水生植物的耐污程度及其对水质和底 质等条件的需求, 选取几种适宜的水生植物在围隔内进行移栽与群落构建, 并以不移栽水生植物的围隔和围隔外水体作 为对照. 实验期间 (2011 年 4 月至 2012 年 6 月), 围隔内移栽的几种水生植物全部存活,并建立了相对稳定的群落. 同时 还跟踪监测了 3 个处理组的水质情况, 结果显示, 移栽水生植物的围隔内水质明显优于围隔外, 与未移栽水生植物围隔相 比, 也有很大程度的改善, 其中移栽水生植物围隔内水体的总氮、铵态氮、总磷、水下消光系数相比于围隔外水体分别低 $30.55 \% 、 44.09 \% 、 36.04 \%$ 和 $42.13 \%$, 相比于未移栽水生植物围隔内水体分别低 $5.96 \% 、 13.40 \% 、 6.70 \%$ 和 $7.60 \%$, 透 明度分别比围隔外水体和未移栽水生植物围隔水体高 $74.59 \%$ 和 $8.70 \%$, 浮游植物生物量也大大低于围隔外, 而浮游动 物生物量却明显高于后者. 此外, 实验后移栽水生植物围隔内沉积物氮、磷含量及其间隙水总氮、总磷、铵态氮浓度明显 低于围隔外和未移栽水生植物围隔. 研究表明, 在富营养化浅水湖泊中通过建立围隔进行合理的群落配置, 进而逐步恢 复水生植物是完全可行的,而水生植物恢复后加强对其管理和维护至关重要.
\end{abstract}

关键词: 水生植物; 围隔;富营养化;浅水湖泊;生态恢复

\section{Restoration of aquatic vegetation and its ecological effects in the enclosure of an eutroph- ic lake}

\author{
HU Xu ${ }^{1}$, HE Liang ${ }^{2}$, CAO Te ${ }^{2}$, NI Leyi ${ }^{2} \&$ XIE Ping ${ }^{1,2}$ \\ (1: College of Fisheries, Huazhong Agricultural University, Wuhan 430070, P. R. China) \\ (2: Institute of Hydrobiology, Chinese Academy of Sciences, Wuhan 430072, P. R. China)
}

\begin{abstract}
Eutrophication induces aquatic vegetation decline, cyanobacterial bloom, deterioration of water quality, and regime shifts in shallow lakes. Restoration of aquatic vegetation is considered as an important approach to improve water quality and enhance ecosystem stability. In this study, we transplanted aquatic macrophytes in large enclosures with temporal aids of water treatments and selecting aquatic macrophyte species according to their habitat preferences. Ecological effects of the transplantation were examined by comparing water chemicals and biological indices in the enclosures with and without aquatic macrophytes, and in the open water in the lake out of the enclosures. During the experimental period (from April 2011 to June 2012), all macrophytes in the enclosure survived and built relatively stable communities. The water quality was better in the enclosure with aquatic vegetation than in area without vegetation, concentrations of total nitrogen, ammonium nitrogen, total phosphorus and light extinction in water in the vegetated enclosure decreased by $30.55 \%, 44.09 \%, 36.04 \%$ and $42.13 \%$, respectively. In comparison, in the open water, they decreased by $5.96 \%, 13.40 \%, 6.70 \%$ and $7.60 \%$, respectively. Secchi depth increased by $74.59 \%$ and $8.70 \%$ as compared to the open water and the enclosure without aquatic vegetation, respectively, phytoplankton biomass was lower and zooplankton biomass was higher in the vegetated enclosure than in the one without aquatic vegetation and in the open water. In addition, aquatic vegetation tended to decrease the contents of total nitrogen and phosphorus in sediments and porewater of sediments and ammonium nitrogen concentrations in the porewater of sediments, but did not affect phosphate and nitrate in porewater of sedi-
\end{abstract}

* 国家自然科学基金项目 (31270508) 和国家水体污染控制与治理科技重大专项项目(2012ZX07105-004)联合资助. 2013-04-27 收稿;2013-11-19 收修改稿. 胡旭(1985 ), 男, 硕士研究生; E-mail : huxunmg@ 163. com.

** 通信作者;E-mail:xieping@ ihb. ac. cn. 
ments. The study implied that selection of eutrophication tolerant aquatic macrophytes species facilitated restoration of aquatic vegetation and thus improve water quality in eutrophic lakes.

Keywords: Aquatic macrophytes; enclosure; eutrophication; shallow lake; ecological restoration

水体富营养化导致沉水植被衰退、蓝藻水华暴发、水质恶化和水生生态系统崩溃, 这是我国湖泊当前存 在的普遍问题 ${ }^{[-5]}$. 武汉东湖是典型的富营养化湖泊, 多年来, 随着周边人口增加和产业发展, 大量的生活污 水和工业废水排入湖中. 东湖由 $1950 \mathrm{~s}$ 中营养湖泊至 $1970 \mathrm{~s}$ 变为重富营养湖泊 ${ }^{[6]}$. 湖中水生植物大面积消 失, 透明度降低, 造成生物多样性下降和湖泊生态系统退化 ${ }^{[7-8]}$, 蓝澡水华也曾在 $1980 \mathrm{~s}$ 大面积暴发, 导致水 质恶化. 其中以水果湖湾最为严重 ${ }^{[9]}$, 严重影响了水资源的利用及其功能的发挥.

水生植物是湖泊生态系统的重要组成部分, 具有显著的初级生产功能和环境生态功能. 研究揭示, 在藻 型富营养化浅水湖泊中, 高等水生植物一方面可以通过化感作用直接抑制藻类生长 ${ }^{[10-12]}$, 另一方面可以吸 收水体及沉积物中的营养盐、减少沉积物再悬浮、为摄食藻类的浮游动物提供栖息地及躲避鱼类捕食的庇 护场所, 从而提高水体的透明度并改善水质 ${ }^{[13-17]}$, 维持湖泊的清水稳态和物种多样性 ${ }^{[18-19]}$. 因此, 恢复水生 植被被认为是改善水体水质和提高生态系统稳定性的重要手段 ${ }^{[20]}$. 国内外虽然在相关方面做了大量的尝 试, 结果却不尽如人意, 水生植被重建过程困难重重, 人工修复初步建立起来的植被缺乏稳定性, 辅助措施 取消后水生植物也随之消失. 原因可能是多方面的, 较低的透明度、过高的营养盐含量、频繁的扰动、大量的 悬浮物等都不利于水生植物的生长扩展. 其次, 不同种类的水生植物其生活习性及耐污能力均存在巨大差 异,所以水生植被恢复时, 不适宜的物种选择及群落配置也可能导致恢复失败.

本研究通过构建大型围隔, 并对围隔内水体环境进行了适当的改善, 根据不同种类植物的耐污程度及 其对水质和底质等条件的需求, 结合当地曾经存在较好的植物群落结构, 选取几种适宜的水生植物在围隔 内进行移栽, 并跟踪监测水体水质和植物的生长状况, 探讨水生植物恢复的方式及影响恢复成败的可能因 素, 并分析水生植物恢复与水体环境的相互关系.

\section{1 材料与方法}

\section{1 实验地点与材料}

本实验在我国最大的市内湖泊武汉东湖水果湖湾进行, 平均水深为 $1.5 \mathrm{~m}$, 实验区在本实验开始前无任 何水生植物生长, 为典型的富营养化湖泊. 实验于 2011 年 4 月开始, 至 2012 年 6 月结束. 实验共设置 3 个处 理, 分别为: 建立围隔并移栽水生植物 (有植被)、建立围隔不做任何处理 (无植被)、围隔外 (东湖). 围隔用 防水布固定于铁制栏杆而成, 底部压人底泥, 围隔内外水体不交换. 每个围隔的面积约 $600 \mathrm{~m}^{2}$.

围隔建好后, 为营造适宜水生植物生长的水体环境, 向将移栽水生植物的围隔中撒人黏土约 $400 \mathrm{~kg}$, 具 体方法为向黏土中加适量围隔水摚拌成悬浊液, 均匀的泼洒于围隔中. 静置 $2 \mathrm{~d}$ 后, 围隔水体中的悬浮物质 明显减少, 透明度由 $0.7 \mathrm{~m}$ 升高到 $1.2 \mathrm{~m}$. 此外, 为减少鱼类对水生植物的捕食和扰动作用, 清除围隔中的植 食性鱼类及其它体型较大的鱼类.

实验中恢复的水生植物为: 苦草、金鱼藻、狐尾藻、蕰草、荇菜、菱、大茨藻、马来眼子菜及黑藻 (表 1 ). 所 有水生植物均购于武汉秀水生态工程有限公司. 在水深小于 $1 \mathrm{~m}$ 的沿岸浅水区域移栽浮叶植物荇菜、菱及 沉水植物苦草, 水深 $1.0 \sim 1.9 \mathrm{~m}$ 区域移栽沉水植物金鱼藻、狐尾藻、薄草、大茨藻、马来眼子菜及黑藻. 整个 实验的操作流程如图 1 所示.

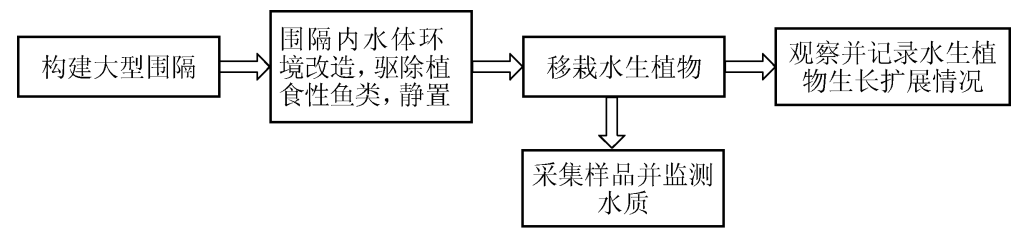

图 1 围隔内水生植物恢复操作流程

Fig. 1 Steps of the restoration of aquatic macrophytes in the enclosure 


\section{2 样品采集及分析}

建立围隔并移栽水生植物后, 每种处理设置 3 个采样点进行样品采集和监测, 并观察记录围隔内水生 植物的恢复生长情况、分布面积及盖度. 样品采集和水质监测频率为每周 1 次. 采集水样、浮游植物和浮游 动物样品, 其中水样用于测定水体中总氮 $(\mathrm{TN}) 、$ 硝态氮 $\left(\mathrm{NO}_{3}^{-}-\mathrm{N}\right)$ 、铵态氮 $\left(\mathrm{NH}_{4}^{+}-\mathrm{N}\right)$ 、总磷 $(\mathrm{TP})$ 、正磷酸盐 $\left(\mathrm{PO}_{4}^{3-}-\mathrm{P}\right)$ 及叶绿素 $\mathrm{a}(\mathrm{Chl} . \mathrm{a})$. 测定参照黄祥飞 ${ }^{[21]}$ 的方法. 使用美国 YSI 公司生产的 YSI 多参数水质监测仪 测定水体的 $\mathrm{pH}$ 值、电导率 (COND)、溶解氧 ( DO)、水温 ( T) , 水下辐射采用 Li-Cor 公司生产的 LI-192SA 探 头和 Li-1000 数据采集器测定, 水下消光系数 $(\mathrm{Kd})$ 计算参考 $\mathrm{Kirk}^{[22]}$ 的方法. 水体透明度 (SD) 用透明度盘测 定, 水深 (Dep) 用测深锤测定. 实验开始前和结束后各处理皆采集 1 次表层沉积物,离心后底泥样品冷冻干 燥研磨后用于测定底泥中的总氮和总磷, 用硫酸一双氧水消化比色法进行测定, 离心出的水样用于测定间隙 水中的 $\mathrm{TN} 、 \mathrm{NO}_{3}^{-}-\mathrm{N} 、 \mathrm{NH}_{4}^{+}-\mathrm{N} 、 \mathrm{TP}$ 和 $\mathrm{PO}_{4}^{3-}-\mathrm{P}$.

\section{3 数据统计分析}

实验中所获得的每个处理组的 3 个采样点的所有数据的方差齐性检验、方差分析和多重比较检验采用 PASW Statistics 18.0 数据分析软件完成, $P<0.05$ 时统计上认为是显著的, 文中所有数据为平均值 \pm 标准 差, 不同字母表示差异显著 $(P<0.05)$.

\section{2 结果}

\section{1 围隔内水生植物的生存扩展情况}

围隔内移栽的几种水生植物全部存活, 并建立起相对稳定的群落. 在向围隔内移栽 水生植物前, 经过适当改善的围隔水体比较 适合水生植物的存活生长. 随着季节和温度 的变化,围隔内的水生植物也有所不同. 冬、 春季主要为沉水植物菹草, 其盖度一度达到 $80 \%$ 以上, 在此期间, 其他植物分布较少. 随 着温度的升高, 到 6 月份, 菹草逐渐调亡, 而 其他植物开始蓬勃生长. 其中苦草、狐尾藻、 菱和荇菜的盖度都达到 $10 \%$ 以上,金鱼藻更 是达到围隔水面的 $20 \%$ 以上, 其他几种水生 植物种群扩增较慢, 在围隔内零星分布. 此 外,春季围隔内有大量的水绵 (Spirogyra sp.) 生长. 在 2012 年 6 月实验结束时, 围隔内的

表 1 围隔内水生植物组成及其盖度

Tab. 1 List of aquatic macrophytes and their coverage in the enclosure

\begin{tabular}{lcc}
\hline 水生植物 & 分布面积 $/ \mathrm{m}^{2}$ & 盖度 $/ \%$ \\
\hline 苦草( Vallisneria natans) & 65 & 10.83 \\
金鱼藻 ( Ceratophyllum demersum) & 150 & 25.00 \\
狐尾藻( Myriophyllum spicatum) & 60 & 10.00 \\
荇菜( Nymphoides peltatum) & 100 & 16.67 \\
菱( Trapa bispinosa) & 80 & 13.33 \\
菹草( Potamogeton crispus) & 5 & 0.83 \\
大茨藻( Najas marina) & 8 & 1.33 \\
马来眼子菜 ( Potamogeton malaianus) & 2 & 0.33 \\
黑藻 (Hydrilla verticillata) & 2 & 0.33 \\
\hline
\end{tabular}
水生植物总盖度接近 $80 \%$. 具体分布面积及其盖度见表 1 .

\section{2 不同处理组水体的水质变化}

首先从氮营养盐含量来看,有植被组、无植被组和东湖水体 TN 浓度分别为 $1.593 、 1.694$ 和 2. $216 \mathrm{mg} / \mathrm{L}$, 有植被组 TN 含量显著低于东湖,相比无植被组也略低,但不显著(表 2); 月际变化上,3 个处理组的 TN 浓度 没有明显的季节变化,但东湖 TN 浓度始终高于 2 个围隔, 有植被组与无植被组之间差异不显著 $(P>0.05)$ (图 2A). 有植被组、无植被组和东湖水体 $\mathrm{NH}_{4}^{+}-\mathrm{N}$ 浓度分别为 $0.175 、 0.202$ 和 $0.313 \mathrm{mg} / \mathrm{L}, 3$ 个处理组两两 之间差异显著 $(P<0.05)\left(\right.$ 表 2); 月际变化上,3 个处理组的 $\mathrm{NH}_{4}^{+}-\mathrm{N}$ 浓度一直表现为夏季高、其它时间较低 的趋势 (图 2C). 有植被组、无植被组和东湖水体 $\mathrm{NO}_{3}^{-}-\mathrm{N}$ 浓度分别为 $0.428 、 0.434$ 和 $0.390 \mathrm{mg} / \mathrm{L}$, 有植被组 与无植被组要略高于东湖,但三者之间差异不显著 $(P>0.05)$ (表 2 ) ; 月际变化上看, 3 个处理组的 $\mathrm{NO}_{3}^{-}-\mathrm{N}$ 浓度都具有明显的冬季高、其它季节较低的趋势 ( 图 2E).

在磷营养盐含量上,有植被组、无植被组和东湖水体 TP 浓度分别为 $0.126 、 0.135$ 和 $0.197 \mathrm{mg} / \mathrm{L}$, 东湖 $\mathrm{TP}$ 浓度显著高于无植被组和有植被组,无植被组与有植被组之间无显著差异 $(P>0.05)($ 表 2$)$; 月际变化 上,东湖 TP 浓度无明显的季节变化,但 2 个围隔的季节变化明显,表现为冬季低,夏、秋季较高 (图 2B). 有 
植被组、无植被组和东湖水体 $\mathrm{PO}_{4}^{3-}-\mathrm{P}$ 浓度分别为 $0.029 、 0.039$ 和 $0.025 \mathrm{mg} / \mathrm{L}, 2$ 个围隔水体 $\mathrm{PO}_{4}^{3-}-\mathrm{P}$ 浓度略 高于东湖, 但三者之间差异不显著 $(P>0.05)$ (表 2); 月际变化上看, 3 个处理组的 $\mathrm{PO}_{4}^{3-}-\mathrm{P}$ 浓度具有相同的 季节变化趋势,都表现为夏季高、其它时间较低 (图 2D).
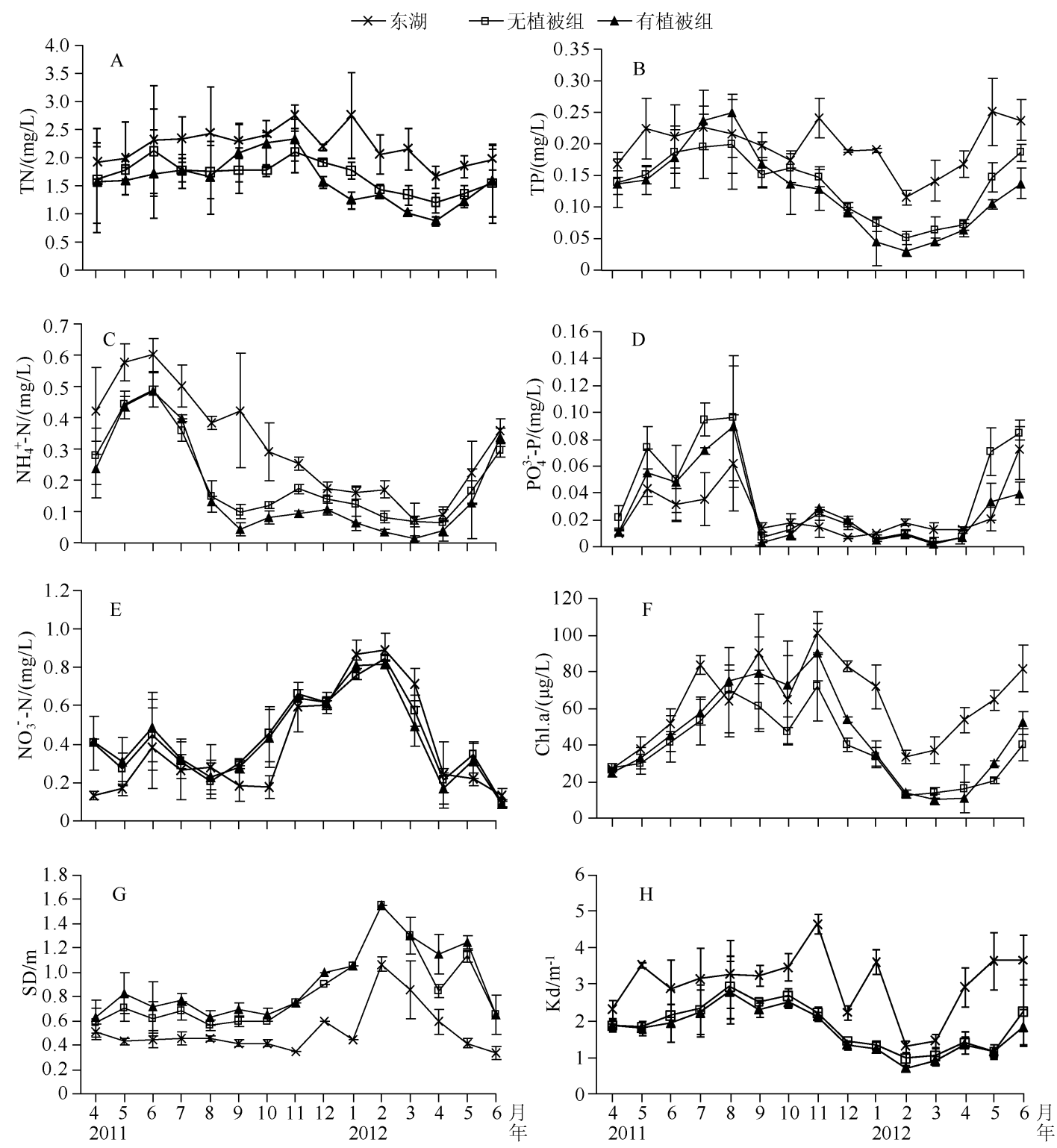

图 2 不同处理组的物理化学指标月际变化

Fig. 2 Monthly variation of physicochemical parameters in different treatments

有植被组、无植被组和东湖水体 Chl. a 浓度分别 45.573 、38.481 和 $62.944 \mu \mathrm{g} / \mathrm{L}$, 东湖水体 Chl. a 浓度 显著高于无植被组与有植被组水体, 无植被组与有植被组之间也具有显著差异 $(P<0.05)$ (表 2 ); 从月际变 化上来看, 3 种处理组均表现出明显的夏、秋季高, 其它时间较低的趋势 (图 $2 \mathrm{~F}$ ). 有植被组、无植被组和东湖 水体 SD 分别为 $0.908 、 0.835$ 和 $0.521 \mathrm{~m}$,东湖和无植被组的 SD 显著低于有植被组, 东湖 SD 也显著低于无 植被组 $(P<0.05)$ (表 2 ); 月际变化上 3 种处理组都明显的表现为冬季高、其它时间低( 图 $2 \mathrm{G}$ ). 有植被组、 
无植被组和东湖水体 $\mathrm{Kd}$ 分别为 $1.762 、 1.906$ 和 $3.045 \mathrm{~m}^{-1}$, 东湖和无植被组水体的 $\mathrm{Kd}$ 显著高于有植被组 水体, 东湖水体 $\mathrm{Kd}$ 也显著高于无植被组 $(P<0.05)($ 表 2$)$; 月际变化上 $\mathrm{Kd}$ 与 $\mathrm{SD}$ 相反,3 种处理组都表现为 冬季低、其它时间较高 (图 2H).

总体来看, 有植被组水体除 $\mathrm{NO}_{3}^{-}-\mathrm{N} 、 \mathrm{PO}_{4}^{3-}-\mathrm{P}$ 外, 其它营养盐含量均显著低于东湖水体, 大部分营养盐含 量也低于无植被组水体. 其中有植被组水体 $\mathrm{TN} 、 \mathrm{NH}_{4}^{+}-\mathrm{N}$ 、 $\mathrm{TP}$ 和 $\mathrm{Kd}$ 相比于东湖水体分别低 $30.55 \%$ 、 $44.09 \% 、 36.04 \%$ 和 $42.13 \%$, 相比于无植被组水体分别低 $5.96 \% 、 13.40 \% 、 6.70 \%$ 和 7.60\%. 有植被组水体 Chl. a 浓度比东湖水体低 $27.60 \%$, 而比无植被组水体高 $15.60 \%$. 有植被组水体 SD 分别比东湖水体和无植 被组水体高 $74.59 \%$ 和 $8.70 \%$ (表 2 ).

表 2 不同处理组的水体理化指标比较*

Tab. 2 Comparisons of physicochemical parameters in different treatments

\begin{tabular}{|c|c|c|c|}
\hline 水体理化指标 & 东湖 & 无植被组 & 有植被组 \\
\hline $\mathrm{TN} /(\mathrm{mg} / \mathrm{L})$ & $2.216 \pm 0.312^{\mathrm{a}}$ & $1.694 \pm 0.273^{\mathrm{b}}$ & $1.593 \pm 0.416^{\mathrm{b}}$ \\
\hline $\mathrm{NO}_{3}^{-}-\mathrm{N} /(\mathrm{mg} / \mathrm{L})$ & $0.390 \pm 0.269^{\mathrm{a}}$ & $0.434 \pm 0.218^{\mathrm{a}}$ & $0.428 \pm 0.219^{\mathrm{a}}$ \\
\hline $\mathrm{NH}_{4}^{+}-\mathrm{N} /(\mathrm{mg} / \mathrm{L})$ & $0.313 \pm 0.170^{\mathrm{a}}$ & $0.202 \pm 0.138^{b}$ & $0.175 \pm 0.162^{\mathrm{ab}}$ \\
\hline $\mathrm{TP} /(\mathrm{mg} / \mathrm{L})$ & $0.197 \pm 0.039^{\mathrm{a}}$ & $0.135 \pm 0.051^{\mathrm{b}}$ & $0.126 \pm 0.066^{b}$ \\
\hline $\mathrm{PO}_{4}^{3-}{ }^{-} \mathrm{P} /(\mathrm{mg} / \mathrm{L})$ & $0.025 \pm 0.020^{\mathrm{a}}$ & $0.039 \pm 0.036^{\mathrm{a}}$ & $0.029 \pm 0.027^{\mathrm{a}}$ \\
\hline Chl. a/ $(\mu \mathrm{g} / \mathrm{L})$ & $62.944 \pm 22.556^{\mathrm{a}}$ & $38.481 \pm 19.439^{b}$ & $45.573 \pm 25.907^{\mathrm{ab}}$ \\
\hline $\mathrm{SD} / \mathrm{m}$ & $0.521 \pm 0.197^{\mathrm{a}}$ & $0.835 \pm 0.298^{\mathrm{b}}$ & $0.908 \pm 0.292^{\mathrm{ab}}$ \\
\hline $\mathrm{Kd} / \mathrm{m}^{-1}$ & $3.045 \pm 0.880^{\mathrm{a}}$ & $1.906 \pm 0.620^{\mathrm{b}}$ & $1.762 \pm 0.600^{\mathrm{ab}}$ \\
\hline $\mathrm{DO} /(\mathrm{mg} / \mathrm{L})$ & $8.900 \pm 2.656^{\mathrm{a}}$ & $7.312 \pm 2.696^{\mathrm{b}}$ & $8.356 \pm 2.628^{\mathrm{ab}}$ \\
\hline $\mathrm{pH}$ & $8.499 \pm 0.211^{\mathrm{a}}$ & $8.261 \pm 0.286^{\mathrm{b}}$ & $8.323 \pm 0.283^{\mathrm{b}}$ \\
\hline $\mathrm{COND} /(\mu \mathrm{S} / \mathrm{cm})$ & $357.896 \pm 36.849^{\mathrm{a}}$ & $348.481 \pm 46.561^{\mathrm{b}}$ & $348.102 \pm 43.731^{b}$ \\
\hline $\mathrm{T} /{ }^{\circ} \mathrm{C}$ & $20.335 \pm 8.427^{\mathrm{a}}$ & $19.843 \pm 8.828^{\mathrm{b}}$ & $19.870 \pm 8.792^{\mathrm{b}}$ \\
\hline $\mathrm{TN} / \mathrm{TP}$ & $11.699 \pm 2.809^{\mathrm{a}}$ & $14.592 \pm 6.231^{\mathrm{b}}$ & $16.299 \pm 9.739^{\mathrm{ab}}$ \\
\hline
\end{tabular}

*不同小写字母表示差异显著 $(P<0.05)$.

\section{3 不同处理组的沉积物及间隙水的理化性质变化}

不同处理组沉积物间隙水中各形态氮营养盐实验前后变化较为明显,实验前有植被组、无植被组和东 湖沉积物间隙水 TN 浓度分别为 7.477、7.822 和 $8.379 \mathrm{mg} / \mathrm{L}$, 有植被组和无植被组略低于东湖, 差异不显著 $(P>0.05)$; 实验后, 有植被组、无植被组和东湖沉积物间隙水 TN 浓度分别为 $5.914 、 7.439$ 和 $9.595 \mathrm{mg} / \mathrm{L}$, 有植被组和无植被组显著低于东湖,有植被组亦显著低于无植被组 $(P<0.05)$, 各处理组 $\mathrm{TN}$ 浓度实验后与 实验前相比, 东湖显著升高, 有植被组显著降低 $(P<0.05)$, 降幅为 $20.91 \%$. 而无植被组 $\mathrm{TN}$ 浓度实验前后 无显著差异 $\left(P>0.05\right.$ ) (图 3A). 实验前有植被组、无植被组和东湖 $\mathrm{NH}_{4}^{+}-\mathrm{N}$ 浓度分别为 5. 124、5.382 和 $6.315 \mathrm{mg} / \mathrm{L}$, 有植被组与无植被组显著低于东湖, 而有植被组与无植被组之间差异不显著 $(P>0.05)$; 实验 后,有植被组、无植被组和东湖间隙水 $\mathrm{NH}_{4}^{+}-\mathrm{N}$ 浓度分别为 $2.748 、 3.597$ 和 $7.174 \mathrm{mg} / \mathrm{L}$, 有植被组与无植被 组显著低于东湖,有植被组显著低于无植被组 $(P<0.05), 3$ 种处理组 $\mathrm{NH}_{4}^{+}-\mathrm{N}$ 浓度实验后与实验前相比, 东 湖显著升高, 而无植被组与有植被组都显著降低, 其中有植被组 $\mathrm{NH}_{4}^{+}-\mathrm{N}$ 浓度降低 46. 37\% (图 3C). 实验前, 有植被组、无植被组和东湖沉积物间隙水 $\mathrm{NO}_{3}^{-}-\mathrm{N}$ 浓度分别为 $0.093 、 0.123$ 和 $0.143 \mathrm{mg} / \mathrm{L}$, 有植被组显著低于 无植被组和东湖; 实验后, 植被组、无植被组和东湖沉积物间隙水 $\mathrm{NO}_{3}^{-}-\mathrm{N}$ 浓度分别为 $0.112 、 0.129$ 和 $0.170 \mathrm{mg} / \mathrm{L}$, 有植被组与无植被组显著低于东湖 $(P<0.05)$, 与实验前相比, 有植被组和东湖沉积物间隙水 $\mathrm{NO}_{3}^{-}-\mathrm{N}$ 浓度比实验前显著升高 $(P<0.05)$, 无植被组与实验前无显著差异 $(P>0.05)$ ( 图 3E).

实验前, 植被组、无植被组和东湖沉积物间隙水 TP 浓度分别为 $0.332 、 0.333$ 和 $0.367 \mathrm{mg} / \mathrm{L}$, 有植被组 与无植被组显著低于东湖 $(P<0.05)$; 实验后, 分别为 $0.259 、 0.319$ 和 $0.390 \mathrm{mg} / \mathrm{L}, 3$ 种处理组两两之间差 异显著 $(P<0.05)$, 与实验前相比,有植被组沉积物间隙水 TP 浓度显著降低 $(P<0.05)$, 降低约 $21.99 \%$, 无 植被组实验前后无显著差异 $(P>0.05)$, 而东湖沉积物间隙水 TP 浓度比实验前显著升高 $(P<0.05)($ 图 $3 \mathrm{~B})$. 实验前, 植被组、无植被组和东湖沉积物间隙水 $\mathrm{PO}_{4}^{3-}-\mathrm{P}$ 浓度分别为 $0.151 、 0.152$ 和 $0.165 \mathrm{mg} / \mathrm{L}$, 三者 
之间无显著差异 $(P>0.05)$; 实验后, 分别为 $0.167 、 0.149$ 和 $0.181 \mathrm{mg} / \mathrm{L}$, 有植被组与东湖显著高于无植被 组 $(P<0.05)$, 与实验前相比, 有植被组与东湖均显著升高 $(P<0.05)$, 无植被组与实验前相比无显著差异 $(P>0.05)$ ( 图 3D).
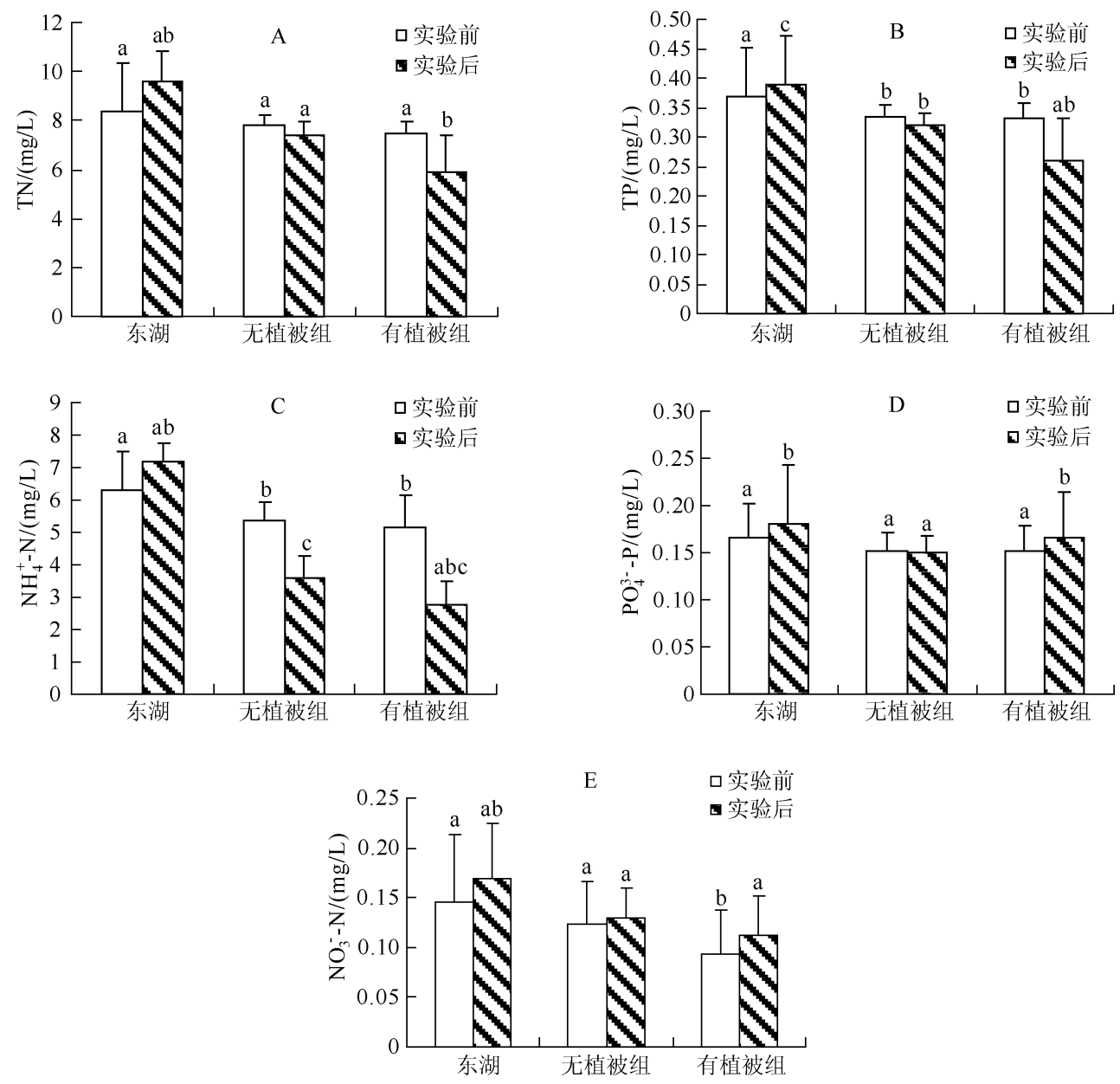

图 3 实验前后不同处理组的间隙水水质指标变化

Fig. 3 Variations of water chemistry in interstitial water in different treatments at the beginning and the end of the experiment

各处理组实验前后沉积物中氮、磷含量变化来看, 有植被组沉积物氮、磷含量变化均较为明显, 无植被 组氮含量变化也比较明显, 而东湖氮、磷含量实验前后无明显的变化. 氮含量上, 实验前 3 种处理组分别为: 有植被组 $0.469 \%$ 、无植被组 $0.468 \%$ 、东湖 $0.512 \%$, 东湖显著高于有植被组和无植被组, 有植被组与无植 被组之间无显著差异 $(P>0.05)$; 实验后, 有植被组氮含量为 $0.394 \%$, 无植被组氮含量为 $0.406 \%$, 东湖氮 含量为 $0.535 \%$, 东湖显著高于有植被组和无植被组 $(P<0.05)$, 有植被组与无植被组之间无显著差异 $(P>$ 0.05 ), 与实验前相比, 有植被组与无植被组均显著降低, 东湖略有升高, 但差异不显著 $(P>0.05)$ (图 4A). 磷含量上, 实验前, 3 种处理组分别为: 有植被组 $0.202 \%$, 无植被组 $0.201 \%$, 东湖 $0.223 \%$, 东湖显著高于有 植被组和无植被组, 有植被组与无植被组之间无显著差异 $(P>0.05)$; 实验后 3 种处理组磷含量分别为: 有 植被组 $0.182 \%$, 无植被组 $0.198 \%$, 东湖 $0.236 \%$, 有植被组显著低于无植被组和东湖 $(P<0.05)$, 无植被组 亦显著低于东湖 $(P<0.05)$, 与实验前相比, 有植被组磷含量显著降低, 无植被组和东湖与实验前无显著差 异 $(P>0.05)$ (图 4B). 

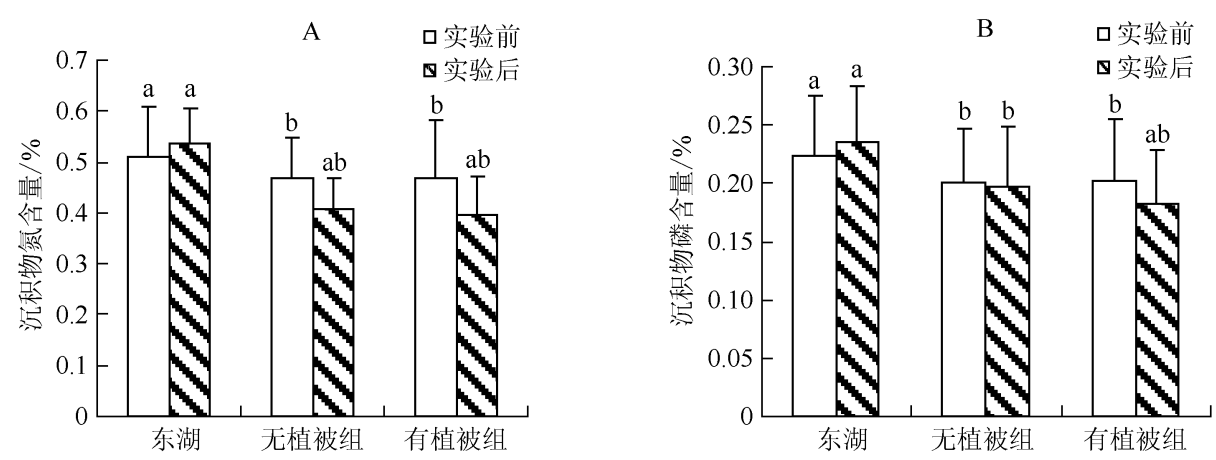

图 4 实验前后不同处理组沉积物氮磷含量变化

Fig. 4 Variations of sediment nitrogen and phosphorus content in different treatments at the beginning and the end of the experiment

\section{4 不同处理组的浮游生物变化}

实验期间,共统计了 2011 年 4 月至 2012 年 3 月一年时间的浮游生物情况. 3 种处理组均鉴定出浮游植 物 7 门. 其中, 绿藻门 (Chlorophyta) 的种类数最多, 其次为蓝藻门 (Cyanophyta) 和硅藻门 (Bacillariophyta), 隐 藻门 (Cryptophyta)、裸藻门(Euglenophyta)、甲藻门 (Pyrrophyta) 和金藻门 (Chrysophyta) 种类数较少. 3 种处 理组在 6-11 月都以蓝藻门占主导地位,约占 60\% 以上,其它月份以硅藻门、隐藻门和绿藻门共同占优势. 从浮游植物总生物量上来看, 东湖的总生物量在绝大部分时间明显高于有植被组和无植被组, 有植被组的 浮游植物总生物量在大部分月份略高于无植被组 ( 图 5 ).

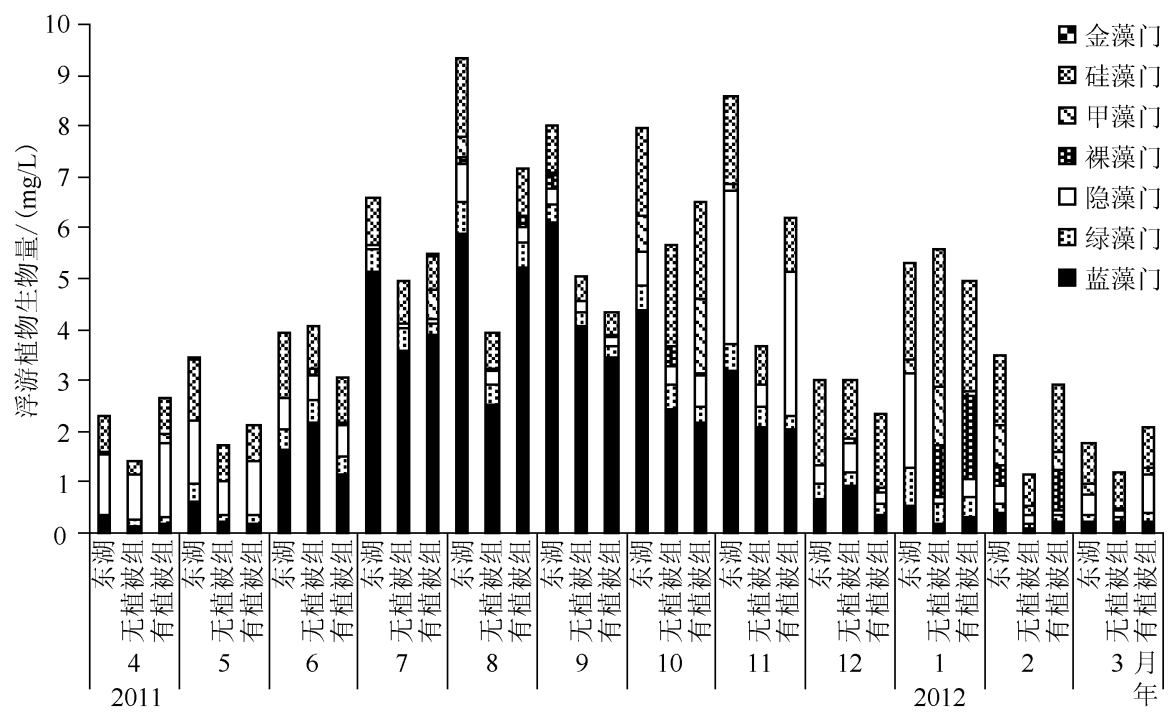

图 5 不同处理组的浮游植物生物量及物种组成月际变化

Fig. 5 Monthly variation of phytoplankton biomass and species composition of different treatments

实验中还统计了浮游动物中的枝角类 (Cladocera) 和桡足类 (Copepoda) 生物量组成的变化. 在 3 种处理 中, 均表现为枝角类在夏、秋季节 $(5-10$ 月) 占主导地位, 桡足类在冬、春季节 (10 月至次年 4 月) 占优势. 总 生物量上,有植被组和无植被组全年都明显高于东湖,有植被组在绝大部分时间略高于无植被组 (图 6), 这 可能与有植被组中稳定适宜的栖息环境且缺少脊椎动物捕食者有关.

\section{3 讨论}

本实验中, 重建水生植物群落对改善水质具有一定的效果. 围隔内移栽的几种水生植物全部存活, 并建 


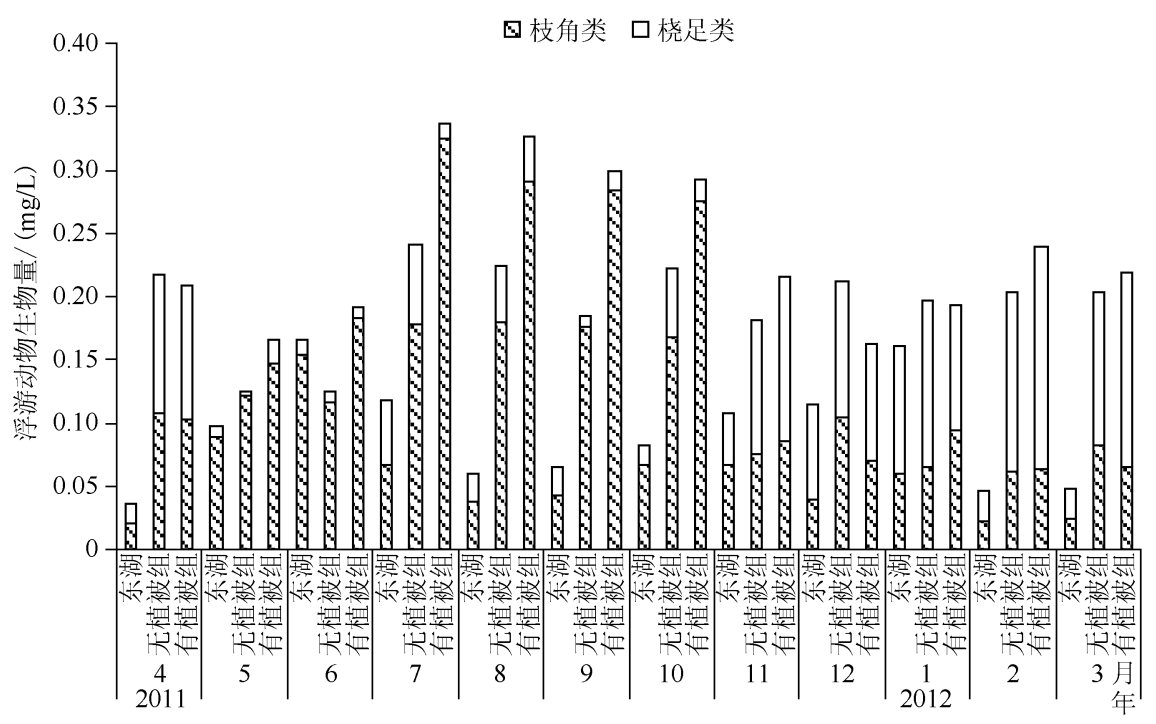

图 6 不同处理组的浮游动物生物量月际变化

Fig. 6 Monthly variation of zooplankton biomass in different treatments

立了相对稳定的群落; 移栽水生植物的围隔内水质明显优于围隔外, 与未移栽水生植物围隔相比, 也有较大 程度的改善. 研究结果表明, 通过建立围隔阻断外源负荷, 适当改善水体环境后, 可以成功地恢复水生植被, 而水生植被重建后, 又进一步改善了围隔内水体水质和生物群落, 实现了围隔水体由以浮游植物占优势的 “浊水态” 向以大型水生植物占优势的 “清水态” 的快速转换 ${ }^{[23]}$, 使得围隔内的生态系统得到良性循环. 值得 注意的是, 在外部邻近水体环境没有得到改善时, 就盲目地拆除围隔, 可能会对已恢复的水生植物造成严重 打击甚至使其消亡. 此外, 这种通过建立围隔, 采用化整为零的方式恢复水生植物的方法, 只适用于水深较 浅、面积较小的湖泊. 而在水深较深、面积较大的湖泊中采用这种方法恢复水生植物可能会面临较大的 困难.

据相关研究报道 ${ }^{[23-24]}$, TN 与 $\mathrm{TP}$ 浓度分别在 2 和 $0.25 \mathrm{mg} / \mathrm{L}$ 以下时, 才有利于水生植物的生长, 浅水湖 泊可以通过水生植物的生长而维持清洁状态, 高于此浓度, 浮游植物将会占优势. 在本实验中, 围隔内的 TN 及 TP 浓度在移栽水生植物初期都较高, 甚至一度高于上述浓度, 但在透明度较高时, 水生植物的生长状况 依然良好, 而透明度较低时, 水生植物生长缓慢甚至衰亡. 从本研究结果来看, 单纯的水中氮、磷浓度高, 并 不是限制水生植物恢复重建的关键因子, 而透明度则显得更加重要. 因此, 在移栽水生植物前, 为保证其移 栽成功,并健康地生长扩展, 首先必须提高水体透明度.

实验过程中,2011 年夏季, 移栽水生植物围隔与未移栽水生植物围隔内均出现一定程度的蓝藻水华, 而 围隔外却没有出现. 从同期的水质监测结果来看, 两个围隔内的浮游植物生物量、叶绿素浓度、氮磷浓度均 低于围隔外, 而浮游动物生物量高于围隔外, 所有以上现象都表明围隔外似乎更可能出现水华, 但结果却恰 恰相反. 经过对 3 种处理组浮游植物生物量的分析发现, 在水华暴发期间, 两个围隔内的蓝藻中, 铜绿微囊 藻 (Microcystis aeruginosa) 的生物量均大大高于围隔外, 而铜绿微囊藻能形成肉眼可见的达数毫米的群体, 这 对浮游动物中的枝角类来说常常是不可食的 ${ }^{[25-27]}$. 且围隔内缺少鲢鳙等滤食性鱼类对群体蓝藻的有效摄 食, 这可能是造成围隔内出现水华的主要原因. 因此, 在水生植物群落重建初期, 由于植物的现存量较小, 结 构不稳定, 群落脆弱而易受破坏, 需要尽可能减少干扰因素的影响, 所以在重建水生植被前适当控制甚至清 除鱼类是必要的, 但当植物群落发展到相对稳定的时候, 可以适当引进水生动物, 使之达到一个平衡. 此外, 围隔内水体环境受外界扰动较小,也使得蓝藻更容易聚集而形成水华.

本研究发现, 实验期间随着季节的变化, 围隔内的优势种群也在发生变化, 这可能与不同植物的最佳生 长季节及其耐污能力存在差异有关. 春季基本以蕰草为主, 其它植物很少见, 进人夏季, 荇菜、苦草、狐尾藻、 金鱼藻相继得以发展, 而后以菱为优势种. 值得注意的是, 春季水绵、刚毛藻曾在围隔内暴发性生长, 严重影 
响了其它植物的生长扩展, 因此,此期间应注意对其管理和控制. 此外, 实验中发现, 荇菜、菱等浮叶植物与 沉水植物的分布区有较大重叠, 浮叶植物导致水下光照降低, 极度不利于沉水植物的发展, 是其有力的竞争 者, 因此, 在水生植被群落重建时, 应适当控制浮叶植物的发展. 实验过程中, 由于夏季雨水较多, 2011 年 7 月,围隔内水位上升接近 $1 \mathrm{~m}$, 给刚恢复的水生植物造成毁灭性打击. 有研究表明, 水位的剧烈波动, 尤其是 持续的高水位, 对水生植物的生长非常不利, 甚至造成植物的死亡 ${ }^{[28]}$, 因此, 在水生植物恢复时, 保持合理的 水位节律至关重要.

致谢: 感谢张培育、吴耀、罗从强、朱天顺等同学在实验过程中给予的帮助.

\section{4 参考文献}

[ 1 ] Ni L. Long-term changes of the structure and biodiversity of aquatic vegetation of Lake Donghu, Wuhan. Acta Hydrobiol, 1996, 20 : 60-74.

[ 2 ] Ni L. Growth of Potamogeton maackianus under low-light stress in eutrophic water. Journal of Freshwater Ecology, 2001, 16: 249-256.

[ 3 ] Ni L. Effects of water column nutrient enrichment on the growth of Potamogeton maackianus A. Been. Journal of Aquatic Plant Management, 2001, 39: 83-87.

[ 4 ] 余国营,刘永定,丘昌强等. 滇池水生植被演替及其与水环境变化关系. 湖泊科学, 2000,12(1):73-80.

[ 5] 谢 平. 微囊藻毒素对人类健康影响相关研究的回顾. 湖泊科学,2009,21:603-613.

[6] 刘建康. 东湖生态学研究 (一). 北京: 科学出版社, 1990 .

[ 7 ] 严国安, 邱东茹. 武汉东湖水生植物群落演替的研究. 植物生态学报, 1997,21:319-327.

[ 8 ] 于 丹,种云霄, 涂芒辉等. 中国水生高等植物受危种的研究. 生物多样性, 1998,6:13-21.

[9] 刘建康. 东湖生态学研究. 北京:科学出版社, 1995.

[10] Gopal B, Goel U. Competition and allelopathy in aquatic plant communities. The Botanical Review, 1993, 59: 155-210.

[11] Søndergaard M, Moss B. Impact of submerged macrophytes on phytoplankton in shallow freshwater lakes. The structuring role of submerged macrophytes in lakes. Netherlands: Springer, 1998:115-132.

[12］俞子文,孙文浩, 郭克勤等. 几种高等水生植物的克藻效应. 水生生物学报,1992,16:1-7.

[13] Gulati RD, Van Donk E. Lakes in the Netherlands, their origin, eutrophication and restoration: state-of-the-art review. Ecological restoration of aquatic and semi-aquatic ecosystems in the Netherlands (NW Europe). Netherlands: Springer, $2002: 73-106$.

[14] Moss B. Engineering and biological approaches to the restoration from eutrophication of shallow lakes in which aquatic plant communities are important components. Biomanipulation tool for water management. Netherlands: Springer, 1990 : 367-377.

[15] Scheffer M, Hosper S, Meijer M et al. Alternative equilibria in shallow lakes. Trends in Ecology \& Evolution, 1993, 8: 275-279.

[16] Schulz M, Kozerski HP, Pluntke T et al. The influence of macrophytes on sedimentation and nutrient retention in the lower River Spree (Germany). Water Research, 2003, 37 : 569-578.

[17] Jeppesen E, Søndergaard M, Kronvang B et al. Lake and catchment management in Denmark. The ecological bases for lake and reservoir management. Netherlands:Springer, 1999:419-432.

[18] Wetzel RG. Structure and productivity of aquatic ecosystems. New York: Saunders College Publishing, 1983.

[19] Scheffer M, Carpenter S, Foley JA et al. Catastrophic shifts in ecosystems. Nature, 2001, 413: 591-596.

[20］许木启,黄玉瑶.受损水域生态系统恢复与重建研究.生态学报, 1998,18:547-558.

[21] 黄祥飞. 湖泊生态调查观测与分析中国生态系统研究网络观测与分析标准方法. 北京: 中国标准出版社, 2000.

[22] Kirk JTO. Light and photosynthesis in aquatic ecosystems. London: Cambridge University Press, 1994.

[23] Sagrario G, María A, Jeppesen E et al. Does high nitrogen loading prevent clear-water conditions in shallow lakes at moderately high phosphorus concentrations? Freshwater Biology, 2005, 50 : $27-41$.

[24] Scheffer M. Ecology of shallow lakes. Netherlands: Springer, 2005.

[25] Arnold DE. Ingestion, assimilation, survival, and reproduction of Daphnia pulex fed seven species of blue-green algae. Response of Daphnia Fed Blue-Green Algae, 1971: 906-920.

[26] Schindler JE. Food quality and zooplankton nutrition. The Journal of Animal Ecology, 1971, 40(3) : 589-595.

[27] 谢 平. 论蓝藻水华的发生机制: 从生物进化,生物地球化学和生态学视点. 北京:科学出版社,2007.

[28] 崔心红,钟 扬,李 伟等. 特大洪水对鄱阳湖水生植物三个优势种的影响. 水生生物学报, 2000,24:322-325. 